\title{
Effects of Chromium Doping on the Electrical Properties of $\mathrm{ZnO}$ Nanoparticles
}

\author{
S. Janet Priscilla ${ }^{a^{*}}$, V. Andria Judi ${ }^{a}$, R. Daniel ${ }^{\text {b }}$, K. Sivaji ${ }^{b}$ \\ ${ }^{a}$ Department of Physics, Madras Christian College, Chennai 600 059, India \\ ${ }^{b}$ Department of Nuclear Physics, University of Madras, Chennai 600 085, India
}

\begin{abstract}
Nanostructured $\mathrm{ZnO}$ has gained a considerable amount of attention due to its unique physical and chemical properties and due to its remarkable performance in the fields of optics, photonics and electronics. The scope of this work is to study the Structural, Optical and Electronic properties of Pure Zinc Oxide $(\mathrm{ZnO})$ and Chromium doped Zinc Oxide nanoparticles. These nanoparticles were synthesized by low-temperature precipitation method at various concentrations in the range $\left(\mathrm{Zn}_{1}\right.$. $\left.{ }_{\mathrm{x}} \mathrm{Cr}_{\mathrm{x}} \mathrm{O} ;(\mathrm{x}=0,0.1 \& 0.3)\right)$. The precursors used were analytical grade Zinc Nitrate Hexahydrate and Chromium Nitrate Nona hydrate. The synthesized nanoparticles were annealed at $400^{\circ} \mathrm{C}$. The Structural property of the synthesized nanoparticles was analysed by XRD (X-Ray diffraction) and was confirmed to exhibit a crystalline hexagonal wurtzite structure with an average crystallite size of $55 \mathrm{~nm}$. The functional groups were analysed using FTIR (Fourier Transformed Infra-red spectroscopy). The Morphology was analysed by FESEM (Field Emission Scanning Electron Microscope) and a change in morphology from spherical to spindle like structure was observed. The Optical properties were analysed using UV-Vis spectroscopy, the absorption spectrum for electromagnetic spectrum was observed and the changes in the optical band gap of $\mathrm{ZnO}$ nanoparticles with Chromium dopant addition were calculated to be in the range of $3.6 \mathrm{eV}$. The Electrical property of the synthesised nanoparticles was analysed using Electrochemical Impedance Spectroscopy (EIS) and the conductivity was calculated to be in the range of $1.1 \mathrm{e}^{-07} \mathrm{~S} / \mathrm{m}$.
\end{abstract}

\section{Keywords:}

$\mathrm{ZnO}$;

Co-precipitation;

Nanoparticles;

XRD;

FTIR.

\section{Article History:}

$\begin{array}{llll}\text { Received: } & 25 & \text { November } & 2019 \\ \text { Accepted: } & 19 & \text { February } & 2020 \\ \text { Published: } & 01 & \text { March } & 2020\end{array}$

\section{1- Introduction}

Zinc Oxide nanoparticles have a wide energy band gap of $3.37 \mathrm{eV}$ and high bond energy $60 \mathrm{MeV}$ [1]. It is active in the ultra-violet region at room temperature. It is a multifunctional material with semiconducting [2], magnetic, optical and electronic properties with a wide range of applications in the field of semiconductors like electronics, optoelectronics, laser technology, solar cells, photo catalysis, sensors, etc. [3]. ZnO has gained interest in the recent years due to its oxidation properties, chemical stability, non-toxic nature and cost-effectiveness. One such application is de-toxing water contaminated with dyes used by the textile industries causing serious effects that may lead to diseases like cancer. There are several ways to treat the waste dyes that are being dumped into the water bodies but are ineffective. Photo catalysis is one of the growing areas of treating organic wastes. It is considered one of the best catalysts in de-toxing water $[4,5]$. $\mathrm{ZnO}$ has maximum optical transparency in visible region of electromagnetic spectrum this property can be altered depending on the dopant added to it. In this work, Zinc Oxide nanoparticles were doped with chromium through low temperature precipitation method. This method was adopted because of its repeatability, homogeneity, control in stoichiometric and cost-effectiveness. The structural, optical and electrical properties of chromium doping in Zinc Oxide nanoparticles synthesized at various concentrations were compared with undoes Zinc Oxide nanoparticles.

\footnotetext{
*CONTACT: Janetpriscilla@gmail.com

DOI: http://dx.doi.org/10.28991/esj-2020-01212
}

(C) 2020 by the authors. Licensee ESJ, Italy. This is an open access article under the terms and conditions of the Creative Commons Attribution (CC-BY) license (https://creativecommons.org/licenses/by/4.0/). 


\section{2- Experimental Details}

\section{2-1- Materials}

The materials used in the synthesis of Pure and Chromium doped Zinc oxide $\left(\mathrm{Zn}_{(1-\mathrm{x})} \mathrm{Cr}_{\mathrm{x}} \mathrm{O} ; \mathrm{x}=0,0.1\right.$ and 0.3 ) nanoparticles are Zinc Nitrate Hex hydrate $\left(\mathrm{Zn}\left(\mathrm{NO}_{3}\right) 2.6 \mathrm{H}_{2} \mathrm{O}\right.$, 99\%), Chromium Nitrate Nona hydrate $(\mathrm{Cr}$ $\left.\left(\mathrm{NO}_{3}\right) 3.9 \mathrm{H}_{2} \mathrm{O}, 96 \%\right)$ and sodium hydroxide pellets $(\mathrm{NaOH}, 97 \%)$. The precursors were purchased with analytical grade and used without any further Purification. Double distilled water was used for making solutions.

\section{2-2- Synthesis of Pure and Cr Doped ZnO Nanoparticles}

Pure and Chromium doped Zinc oxide $\left(\mathrm{Zn}_{(1-\mathrm{x})} \mathrm{Cr}_{\mathrm{x}} \mathrm{O} ; \mathrm{x}=0,0.1\right.$ and 0.3$)$ nanoparticles were synthesized via coprecipitation method. Zinc Nitrate Hexahydrate $\left(\mathrm{Zn}\left(\mathrm{NO}_{3}\right)_{2} \cdot 6 \mathrm{H}_{2} \mathrm{O}\right)$ was dissolved in $100 \mathrm{ml}$ of double distilled water and stirred constantly for 30 minutes. Then, $2 \mathrm{M}$ solution of sodium hydroxide $(\mathrm{NaOH})$ is added until the desired $\mathrm{pH}$ is attained. The milky white solution is heated to $80^{\circ} \mathrm{C}$ for 30 minutes and allowed to age for 18 hours under constant stirring.

The precipitate extracted from the solution by washing and centrifuging at $4000 \mathrm{rpm}$ twice with double distilled water twice with and ethanol, dried at $55^{\circ} \mathrm{C}$ for $36 \mathrm{hrs}$ in the hot air oven. It is then ground well and annealed at 400 ${ }^{\circ} \mathrm{C}$ for 1 hour to obtain pure Zinc Oxide nanoparticles. In the above-mentioned method Chromium Nitrate Nona hydrate $\left(\mathrm{Cr}\left(\mathrm{NO}_{3}\right) 3.9 \mathrm{H}_{2} \mathrm{O}\right)$ was added along with the primary precursor at different weight concentrations to obtain chromium doped Zinc Oxide nanoparticles.

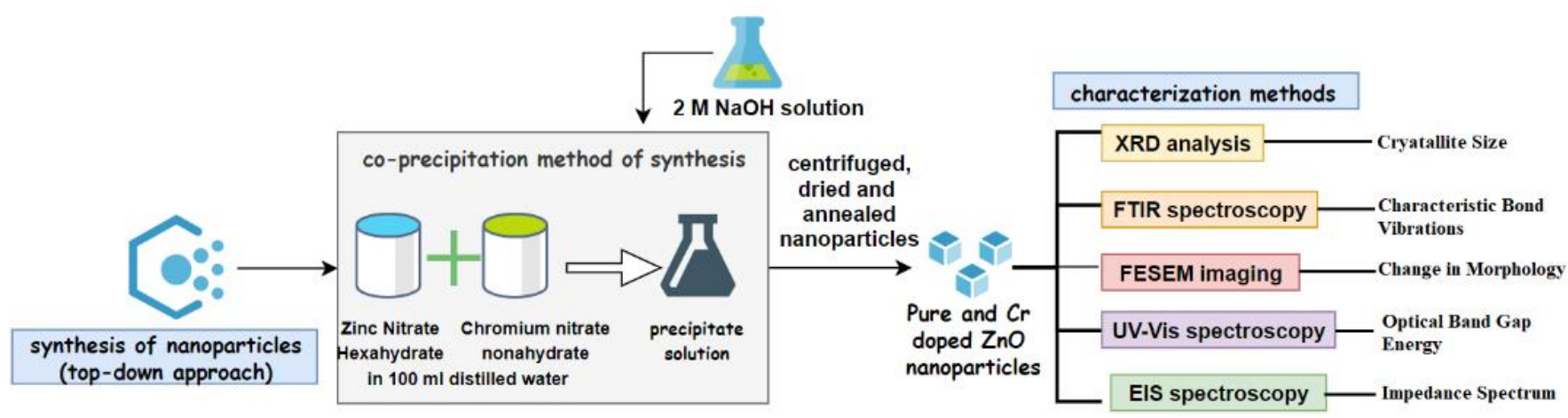

Figure 1. Schematic representation of synthesis of pure and $\mathrm{Cr}$ and $\mathrm{ZnO}$ nanoparticles.

\section{3- Results and Discussion}

\section{3-1-XRD Analysis}

X-Ray Diffraction (XRD) studies the structure and phase information of the synthesized nanoparticles using CuK $\alpha$ radiation of wavelength $1.5406 \mathrm{~A}^{\circ}$ in the range $(2 \theta) 20^{\circ}$ to $70^{\circ}$. Pure and $\mathrm{Cr}$ doped $\mathrm{ZnO}$ nanoparticles exist in hexagonal wurtzite $\mathrm{ZnO}$ structure corresponding to the crystal planes (100), (002), (101), (102), (110), (103), (200), (112) and (201) for pure and (220), (311) and (400) for Cr doped $\mathrm{ZnO}$ [6, 7]. The formed peaks are found to increase in intensity with increase in dopant concentration indicating the presence of Chromium atoms in the lattice, the increase in crystallinity and the absence of impurities.

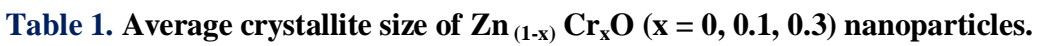

\begin{tabular}{cc}
\hline Concentration & Average crystallite size $\mathbf{D}(\mathbf{n m})$ \\
\hline $\mathrm{Zn}_{(1-\mathrm{x})} \mathrm{Cr}_{\mathrm{x}} \mathrm{O}(\mathrm{x}=0)$ & 50 \\
$\mathrm{Zn}_{(1-\mathrm{x})} \mathrm{Cr}$ & $\mathrm{O}(\mathrm{x}=0.1)$ \\
$\mathrm{Zn}_{(1-\mathrm{x})} \mathrm{Cr}_{\mathrm{x}} \mathrm{O}(\mathrm{x}=0.3)$ & 57 \\
\hline
\end{tabular}




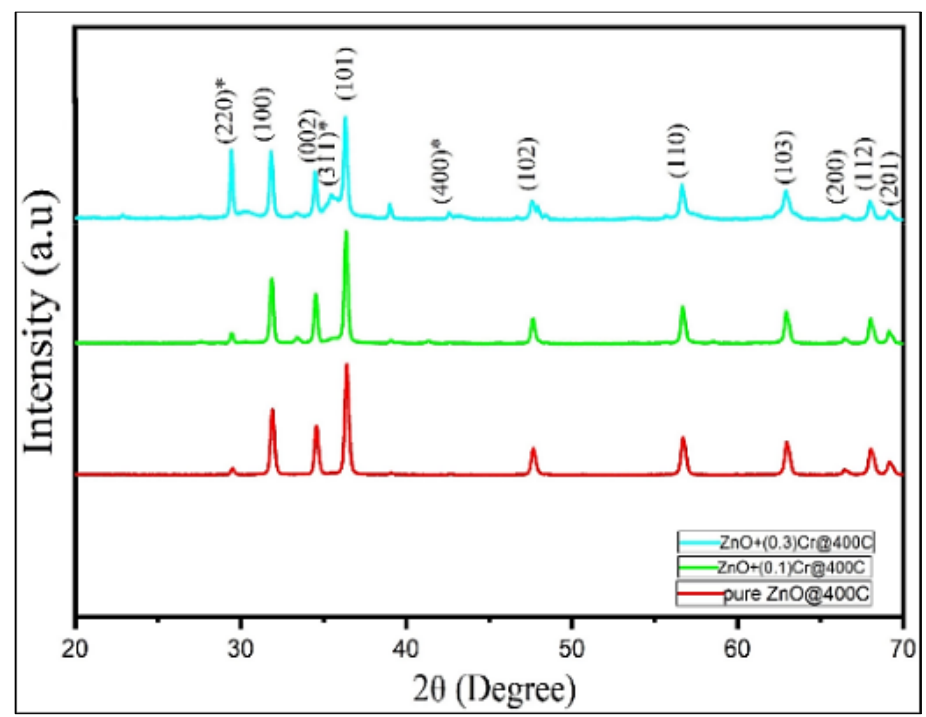

Figure 2. XRD pattern of $\mathrm{Zn}_{(1-\mathrm{x})} \mathrm{Cr}_{\mathrm{x}} \mathrm{O}(\mathrm{x}=\mathbf{0 , 0 . 1}$ and 0.3$)$ nanoparticles.

All the characteristic peaks are in agreement with the JCPDS card no. 36-1451 [8,9]. The average crystallite size is calculated using FWHM in the Scherrer formula $(D=0.9 \times \lambda / \beta \cos \theta)$ and found to increase with increase in dopant concentration. Table 1 gives the average crystallite of $\mathrm{Zn}_{(1-\mathrm{x})} \mathrm{Cr}_{\mathrm{x}} \mathrm{O}(\mathrm{x}=0,0.1$ and 0.3$)$ nanoparticles.

\section{3-2-FTIR Analysis}

The FTIR spectroscopy analyses the functional groups present in the synthesized nanoparticles. The absorption spectra of pure and $\mathrm{Cr}$-doped $\mathrm{ZnO}$ nanoparticles at various concentrations were studied between the wavelengths 400 $\mathrm{cm}^{-1}$ and $4000 \mathrm{~cm}^{-1}$. The characteristic peaks found in the range of 1300 to $1400 \mathrm{~cm}^{-1}, 700$ to $900 \mathrm{~cm}^{-1}$ and 550 to 650 $\mathrm{cm}^{-1}$ is due to $\mathrm{OH}-$ bending vibration [10], Cr-O stretching vibrations and stretching vibration of $\mathrm{ZnO}$ respectively. It also shows that there are no impurities present.

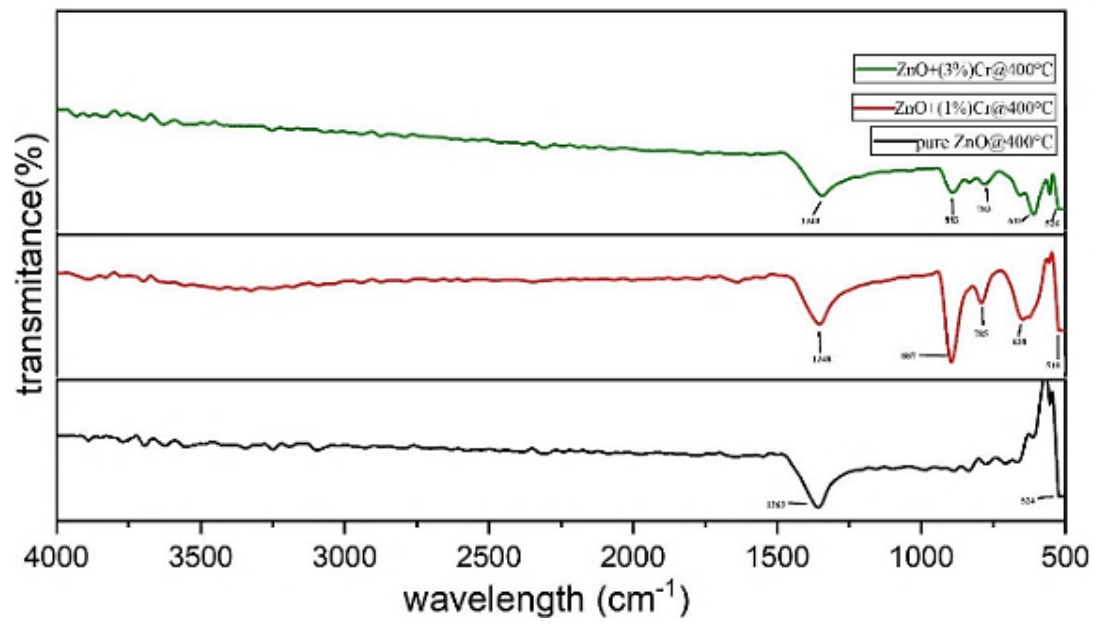

Figure 3. FTIR spectra of $\mathrm{Zn}_{(1-\mathrm{x})} \mathrm{Cr}_{\mathrm{x}} \mathrm{O}(\mathrm{x}=0,0.1$ and 0.3$)$ nanoparticles.

\section{3-3-UV-VIS Analysis}

The UV-Vis absorption spectra for $\mathrm{Cr}$ doped $\mathrm{ZnO}$ nanoparticles are observed between the wavelengths $200 \mathrm{~nm}$ to $800 \mathrm{~nm}$. Strong absorption peaks for pure and $\mathrm{Cr}$ doped $\mathrm{ZnO}$ is found at $341 \mathrm{~nm}, 321 \mathrm{~nm}$ and $320 \mathrm{~nm}$ respectively in the UV region indicating the nanoparticles absorb UV radiation and are transparent to visible radiation of the electromagnetic spectrum [11].

Table 2. Optical band gap energy of $\mathrm{Zn}_{(1-\mathrm{x})} \mathrm{Cr} \mathrm{r}_{\mathrm{x}} \mathrm{O}(\mathrm{x}=\mathbf{0 , 0 . 1}$ and 0.3$)$ nanoparticles.

\begin{tabular}{cc}
\hline Concentration & Optical band gap energy $\mathbf{E}(\mathbf{e V})$ \\
\hline $\mathrm{Zn}_{(1-\mathrm{x})} \mathrm{Cr}_{\mathrm{x}} \mathrm{O}(\mathrm{x}=0)$ & 3.80 \\
$\mathrm{Zn}_{(1-\mathrm{x})} \mathrm{Cr} \mathrm{r}_{\mathrm{x}} \mathrm{O}(\mathrm{x}=0.1)$ & 3.70 \\
$\mathrm{Zn}_{(1-\mathrm{x})} \mathrm{Cr} \mathrm{x}(\mathrm{x}=0.3)$ & 3.61 \\
\hline
\end{tabular}




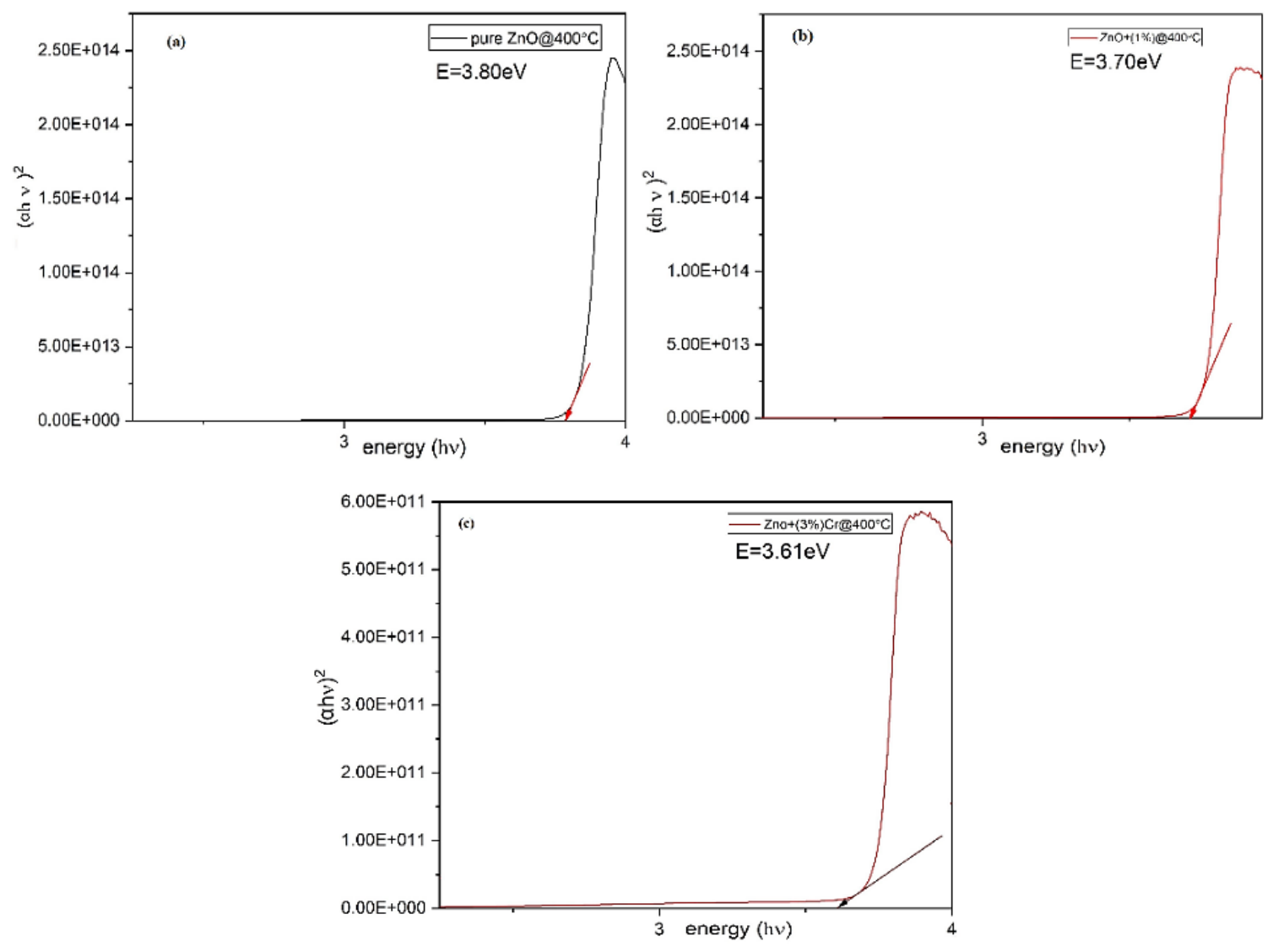

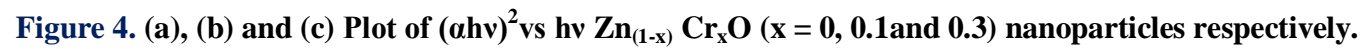

This property the nanoparticles aid in applications such as dye degradation [12]. A plot of $(\alpha h v)^{2} v$ s hv was plotted for pure and $\mathrm{Cr}$ doped $\mathrm{ZnO}$ nanoparticles. The optical band gap energy of the synthesized nanoparticles calculated from the tauc plot is found to be $3.80 \mathrm{eV}, 3.70 \mathrm{eV}$ and $3.61 \mathrm{eV}[13,14]$ for pure and $\mathrm{Cr}$ doped nanoparticles respectively and is found to decrease with increase in dopant concentration as in Table 2.

\section{3-4-FESEM Analysis}

The FESEM imaging technique is used to visualise the morphology and agglomeration of the synthesized nanoparticles [15] from the images it is seen that the pure Zinc Oxide nanoparticles exhibit spherical morphology. It is also found that as the dopant concentration of chromium increases there is more agglomeration leading to increase in crystallite size and change in morphology from spherical to a spindle like structure.
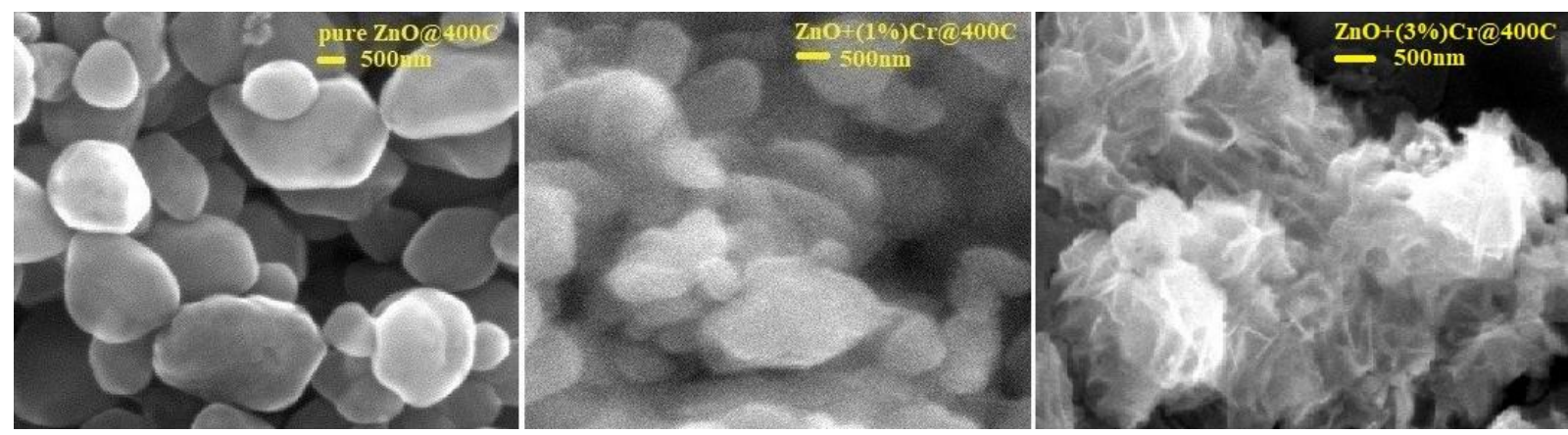

Figure 5. FESEM image of $\mathrm{Zn}_{(1-\mathrm{x})} \mathrm{Cr}_{\mathrm{x}} \mathrm{O}(\mathrm{x}=0,0.1$ and 0.3) nanoparticles respectively.

\section{3-5-Electrochemical Impedance Spectroscopy Analysis}

A Cole-Cole (Nyquist) plot between $Z$ ' and $Z$ ' for pure and chromium doped $\mathrm{ZnO}\left(\mathrm{Zn}_{(1-\mathrm{x})} \mathrm{Cr}_{\mathrm{x}} \mathrm{O}\right.$; $\left.\mathrm{x}=0,0.1 \& 0.3\right)$ was plotted to study the impedance behavior using an AC impedance spectrometer at room temperature [16, 17] several authors have observed a single arc behavior for different nanoscale metal oxide materials resulting in a very narrow relaxation time distribution. 
Table 3. Conductivity of $\mathrm{Zn}_{(1-\mathrm{x})} \mathrm{Cr}_{\mathrm{x}} \mathrm{O}(\mathrm{x}=0,0.1$ and 0.3$)$ nanoparticles.

\begin{tabular}{|c|c|}
\hline Concentration & Conductivity (S/m) \\
\hline $\mathrm{Zn}_{(1-\mathrm{x})} \mathrm{Cr}_{\mathrm{x}} \mathrm{O}(\mathrm{x}=0)$ & $1.115 \mathrm{E}-07$ \\
\hline $\mathrm{Zn}_{(1-\mathrm{x})} \mathrm{Cr}_{\mathrm{x}} \mathrm{O}(\mathrm{x}=0.1)$ & $1.460 \mathrm{E}-07$ \\
\hline $\mathrm{Zn}_{(1-\mathrm{x})} \mathrm{Cr}_{\mathrm{x}} \mathrm{O}(\mathrm{x}=0.3)$ & $1.148 \mathrm{E}-07$ \\
\hline
\end{tabular}
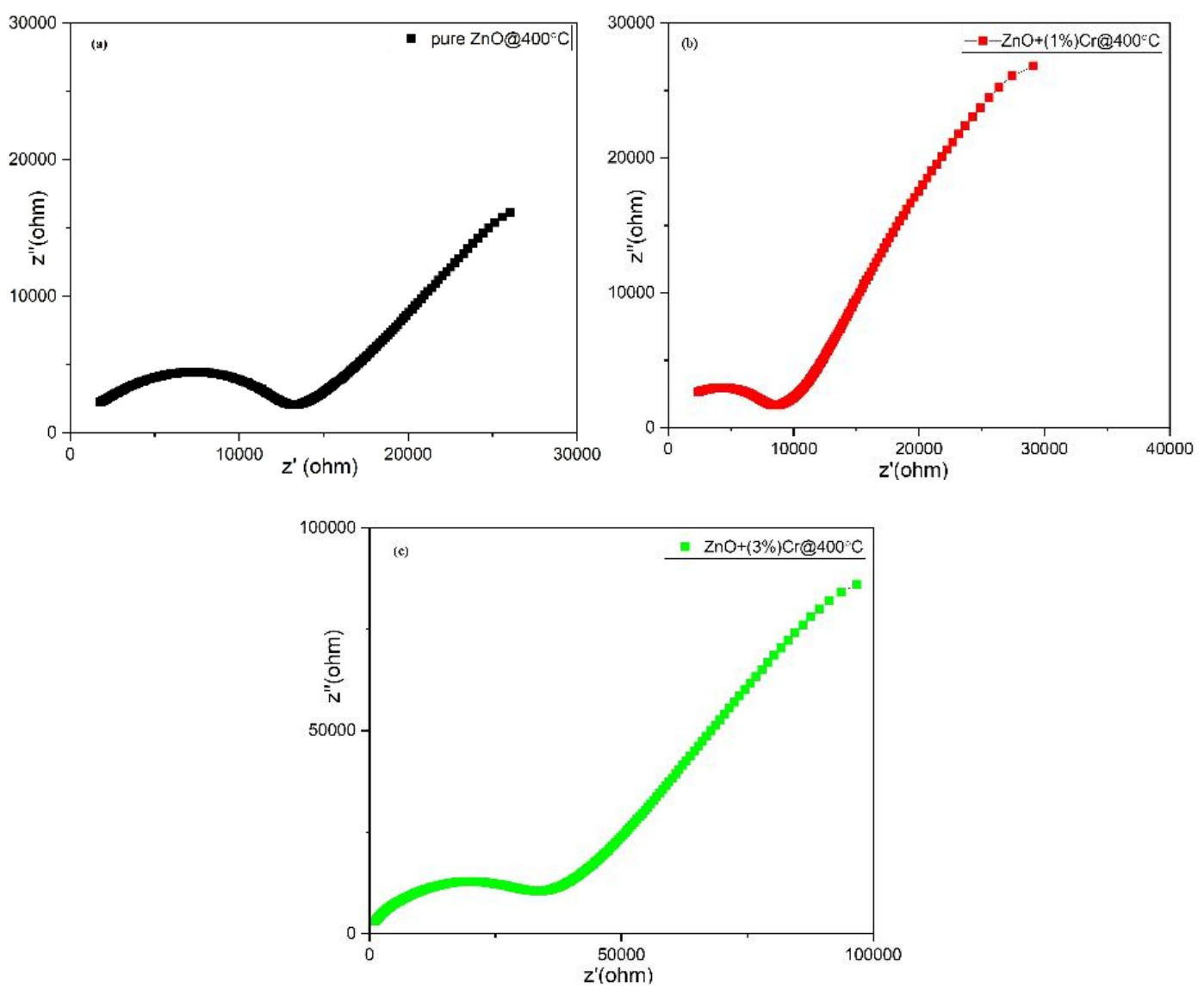

Figure 6. (a), (b) and (c) Cole-Cole plot of $\mathrm{Zn}_{(1-\mathrm{x})} \mathrm{Cr}_{\mathrm{x}} \mathrm{O}(\mathrm{x}=0,0.1$ and 0.3) nanoparticles respectively.

This discrete single relaxation time $\tau$ is due to the above-mentioned behavior which can be calculated from the maximum height of the impedance arc spectrum where, $\tau \omega_{\max }=\mathrm{RC} \omega_{\max }=1\left(\omega_{\max }=2 \pi f_{\max }\right)$ [18]. The impedance spectrum shows two incomplete arc spectra of which the first high-frequency semicircle represents the bulk resistance and the second low-frequency semicircle represents the resistance of the grain boundary. It has an electrical response which is larger compared to the capacitance of the grain core. $\mathrm{ZnO}$ nanoparticles that are doped with transitions metals like Chromium shows an increase and a decrease in the resistance with increase in the dopant concentration. This fashion is observed for concentrations greater than 0.1 compared to that of pure $\mathrm{ZnO}$ [18]. It might also be due to the increase in agglomeration of $\mathrm{Cr}^{3+}$ ions at the grain boundaries as seen in the FESEM images. This condition generates surface acceptors and in turn increases the boundary resistance. The conductivity of the synthesized nanoparticles is found to increase and decrease with the increase in dopant concentration.

\section{4- Conclusion}

Pure and Chromium doped $\mathrm{ZnO}$ nanoparticles were synthesized with various dopant concentrations $\mathrm{Zn}_{(1-\mathrm{x})} \mathrm{Cr}_{\mathrm{x}} \mathrm{O}$; $(\mathrm{x}=0,0.1$ and 0.3 ) by Co-precipitation method using $2 \mathrm{M} \mathrm{NaOH}$ solution as reducing agent. The synthesized nanoparticles were annealed at $400^{\circ} \mathrm{C}$ to remove impurities and the nanoparticles were found to be stable at room temperature. The nanoparticles were characterized using XRD, FTIR Spectroscopy, UV-Visible Spectroscopy, FESEM imaging and EIS Spectroscopy to study the structure, functional groups, optical property, morphology and electrical property respectively. XRD analysis shows that the particles exhibit hexagonal wurtzite structure with an increase in the average crystallite size from $50 \mathrm{~nm}, 57 \mathrm{~nm}$ to $62 \mathrm{~nm}$ respectively with increase in dopant concentration. FTIR spectroscopy shows characteristic vibrations between $1400-1300 \mathrm{~cm}^{-1}, 900-700 \mathrm{~cm}^{-1}$ and $650-500 \mathrm{~cm}^{-1}$ corresponding to $\mathrm{O}-\mathrm{H}$ bending vibration, $\mathrm{Cr}-\mathrm{O}$ stretching vibration and $\mathrm{Zn}-\mathrm{O}$ stretching vibrations respectively. UVVis spectroscopy shows strong absorption peaks in the UV region at $341 \mathrm{~nm}, 321 \mathrm{~nm}$ and $320 \mathrm{~nm}$ with increase in 
dopant concentration indicating the nanoparticles absorb UV radiation and are transparent to visible radiation. A tauc plot of $(\alpha \mathrm{h} v)^{2} \mathrm{vs} \mathrm{h} v$ was plotted and the optical band gap energy is calculated be $3.80 \mathrm{eV}, 3.70 \mathrm{eVand} 3.61 \mathrm{eV}$ and found to decrease with increase in dopant concentration. The FESEM imaging shows the morphology of pure and $\mathrm{Cr}$ doped $\mathrm{ZnO}$ nanoparticles changes from spherical to spindle like structures with increase in dopant concentration.EIS spectroscopy shows the conductivity of the synthesized nanoparticles to be $1.115 \mathrm{e}^{-07} \mathrm{Sm}^{-1}, 1.460 \mathrm{e}^{-07} \mathrm{Sm}^{-1}$ and $1.148 \mathrm{e}^{-07}$ $\mathrm{Sm}^{-1}$ andwas found increase and then decreases as the dopant concentration increases from $\mathrm{x}=0$ to 0.3 respectively. This method of synthesis is found to be energy and cost efficient with good repeatability. The increase in optical activity and the decrease in the optical band gap energy of the synthesized nanoparticles enable various applications.

\section{5- Funding and Acknowledgments}

The authors thank UGC-CPE and DST-FIST for extending financial support and providing research facilities in Madras Christian College, Chennai.

\section{6- Conflict of Interest}

The author declares that there is no conflict of interests regarding the publication of this manuscript. In addition, the ethical issues, including plagiarism, informed consent, misconduct, data fabrication and/or falsification, double publication and/or submission, and redundancies have been completely observed by the authors.

\section{7- References}

[1] Farahmandjou, M., and S. Jurablu. "Co-precipitation synthesis of zinc oxide ( $\mathrm{ZnO}$ ) nanoparticles by zinc nitrate precursor." Int J Bio Inor Hybr Nanomater 3 (2014): 179-84.

[2] Joshi, Zalak, Davit Dhruv, K.N. Rathod, J.H. Markna, A. Satyaprasad, A.D. Joshi, P.S. Solanki, and N.A. Shah. "Size Effects on Electrical Properties of Sol-gel Grown Chromium Doped Zinc Oxide Nanoparticles." Journal of Materials Science \& Technology 34, no. 3 (March 2018): 488-495. doi:10.1016/j.jmst.2017.01.020.

[3] Purwaningsih, S. Y., S. Pratapa, Triwikantoro, and Darminto. "Synthesis of Nano-Sized ZnO Particles by Co-Precipitation Method with Variation of Heating Time" (2016). doi:10.1063/1.4941506.

[4] Ray, Rajeev, Ashavani Kumar, A. K. Paul, and Sachin Tyagi. "Enhanced Photocatalytic Performance of Chromium Doped Zinc Oxide Nanoparticles." Transactions of the Indian Institute of Metals 69, no. 5 (January 16, 2016): $1043-1048$. doi:10.1007/s12666-015-0618-5.

[5] Bhargava, Richa, Prashant K. Sharma, Sanjeev Kumar, Avinash C. Pandey, and Naresh Kumar. "Consequence of Doping Mediated Strain and the Activation Energy on the Structural and Optical Properties of ZnO:Cr Nanoparticles." Journal of Solid State Chemistry 183, no. 6 (June 2010): 1400-1408. doi:10.1016/j.jssc.2010.04.014.

[6] Zhao, Yi, Wenlin Zhou, Yan Wang, Baoyu Gao, Xing Xu, and Yanxia Zhao. "The Effect of Humic Acid and Bovine Serum Albumin on the Adsorption and Stability of ZnO Nanoparticles on Powdered Activated Carbon.” Journal of Cleaner Production 251 (April 2020): 119695. doi:10.1016/j.jclepro.2019.119695.

[7] Salahuddin, Nehal A., Maged El-Kemary, and Ebtisam M. Ibrahim. "Synthesis and characterization of ZnO nanoparticles via precipitation method: effect of annealing temperature on particle size." Nanosci. Nanotechnol 5, no. 4 (2015): 82-88.

[8] Suntako, Rudeerat. "Effect of Zinc Oxide Nanoparticles Synthesized by a Precipitation Method on Mechanical and Morphological Properties of the CR Foam.” Bulletin of Materials Science 38, no. 4 (July 22, 2015): $1033-1038$. doi:10.1007/s12034-015-0921-0.

[9] Ahamed, A. Jafar, and P. Vijaya Kumar. "Synthesis and characterization of ZnO nanoparticles by co-precipitation method at room temperature." Journal of Chemical and Pharmaceutical Research 8, no. 5 (2016): 624-628.

[10] Meng, Alan, Jing Xing, Zhenjiang Li, and Qingdang Li. "Cr-Doped ZnO Nanoparticles: Synthesis, Characterization, Adsorption Property, and Recyclability.” ACS Applied Materials \& Interfaces 7, no. 49 (December 7, 2015): $27449-27457$. doi:10.1021/acsami.5b09366.

[11] Ghorbani, Hamid, Fedos Mehr, Hossein Pazoki, and Behrad Rahmani. "Synthesis of ZnO Nanoparticles by Precipitation Method." Oriental Journal of Chemistry 31, no. 2 (June 20, 2015): 1219-1221. doi:10.13005/ojc/310281.

[12] Li, Zhenjiang, Yongkai Sun, Jing Xing, Yucheng Xing, and Alan Meng. "One Step Synthesis of Co/Cr-Codoped ZnO Nanoparticle with Superb Adsorption Properties for Various Anionic Organic Pollutants and Its Regeneration." Journal of Hazardous Materials 352 (June 2018): 204-214. doi:10.1016/j.jhazmat.2018.03.049.

[13] Kayani, Zohra N., Farhat Saleemi, and Iffat Batool. "Synthesis and Characterization of ZnO Nanoparticles." Materials Today: Proceedings 2, no. 10 (2015): 5619-5621. doi:10.1016/j.matpr.2015.11.100. 
[14] Ray, Rajeev, Ashavani Kumar, A. K. Paul, and Sachin Tyagi. "Enhanced Photocatalytic Performance of Chromium Doped Zinc Oxide Nanoparticles." Transactions of the Indian Institute of Metals 69, no. 5 (January 16, 2016): 1043-1048. doi:10.1007/s12666-015-0618-5.

[15] Salahuddin, Nehal A., Maged El-Kemary, and Ebtisam M. Ibrahim. "Synthesis and characterization of ZnO nanoparticles via precipitation method: effect of annealing temperature on particle size." Nanosci. Nanotechnol 5, no. 4 (2015): 82-88.

[16] Wong, Ka Kan, Annie Ng, Xin Yi Chen, Yip Hang Ng, Yu Hang Leung, Kam Hong Ho, Aleksandra B. Djurišić, et al. "Effect of ZnO Nanoparticle Properties on Dye-Sensitized Solar Cell Performance." ACS Applied Materials \& Interfaces 4, no. 3 (February 22, 2012): 1254-1261. doi:10.1021/am201424d.

[17] Aljawfi, Rezq Naji, F. Rahman, and Khalid M. Batoo. "Effect of Grain Size and Grain Boundary Defects on Electrical and Magnetic Properties of Cr Doped ZnO Nanoparticles.” Journal of Molecular Structure 1065-1066 (May 2014): $199-204$. doi:10.1016/j.molstruc.2014.02.056.

[18] Al-Hardan, N., M.J. Abdullah, and A. Abdul Aziz. "Impedance Spectroscopy of Undoped and Cr-Doped ZnO Gas Sensors Under Different Oxygen Concentrations." Applied Surface Science 257, no. 21 (August 2011): 8993-8997. doi:10.1016/j.apsusc.2011.05.078. 